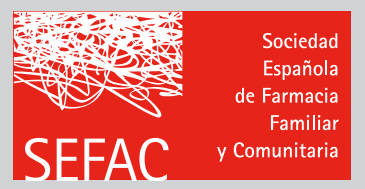

\title{
Farmacéuticos capaces de lo imposible
}

\section{Sonia Saenz de Buruaga}

Presidenta de SEFAC Euskadi y presidenta del comité organizador del IX Congreso Nacional de Farmacéuticos Comunitarios.

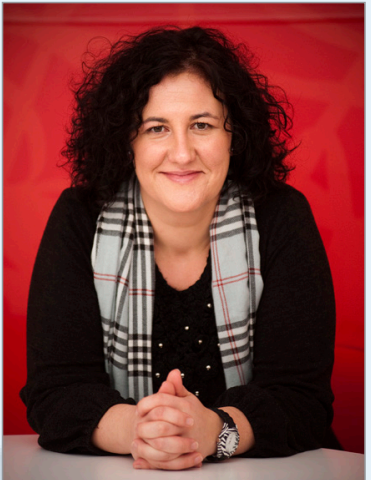

Sonia Saenz de Buruaga

\section{PALABRAS CLAVE}

Farmacéuticos comunitarios, congreso, farmacia asistencial

\section{KEYWORDS}

Community pharmacists, congress, pharmacy
Todos creíamos que era imposible hasta que alguien lo hizo. Puede sonar a bonita frase hecha, pero por muy oída que nos parezca o ajena que nos resulte, es absolutamente real. Parecía imposible que el hombre surcara los cielos y lo hizo, que viajara al espacio y pisara la Luna y lo consiguió, o que enfermedades que no tenían cura hace años la tengan hoy en día. Pero no hace falta mirar tan arriba o muy lejos para percatarse de esto. Todas las personas, a buen seguro, hemos vivido situaciones que jamás imaginamos o hemos llevado a cabo acciones que una vez nos parecieron irrealizables, bien por pereza, inseguridad... bien por ausencia inicial de recursos, formación o motivación, etc.

¿Y como farmacéuticos? ¿Cuántas situaciones hemos vivido o considerado imposibles o de difícil consecución durante nuestro desempeño? Nuestra profesión ha evolucionado mucho y afrontado importantes desafíos en el transcurso del tiempo, lo que nos ha obligado a reinventarnos y a superarnos para seguir ofreciendo la mejor atención posible a los pacientes, aun en condiciones adversas (desabastecimientos, impagos, modificaciones normativas constantes, etc.). Hemos pasado de la formulación a la dispensación, sustentado herramientas como la receta electrónica y hemos dejado de centrarnos en el producto para enfocarnos en la provisión de servicios profesionales asistenciales de cara a satisfacer las demandas de nuestros pacientes y los cambios en el sistema sanitario. También hemos conseguido tener representación como colectivo en foros donde hace años los farmacéuticos no tenían cabida e, incluso, hemos llegado a celebrar congresos conjuntos con médicos para compartir nuestras preocupaciones y formas de trabajar, tal y como hemos comprobado este año por segunda vez en el Congreso Médico \& Farmacéutico SEMERGEN-SEFAC.
Ahora vivimos una nueva etapa de transformación como consecuencia del impacto que están provocando -a todos los niveles- la tecnología y el avance del mundo digital. Esto está cambiando la forma de relacionarse, la actividad económica y profesional, la labor investigadora y científica y la sociedad en su conjunto, generando nuevos escenarios que hace tan solo unas décadas creíamos propios de la ciencia ficción. Como consecuencia de todo esto, no es extraño que surjan dudas sobre nuestras capacidades y sobre lo que nos deparará el futuro. Si estaremos, en definitiva, suficientemente preparados para adaptarnos al curso de los tiempos.

Esa adaptación pasa, en gran parte, por desarrollar la habilidad para concentrarnos en nuestras fortalezas, vislumbrar las oportunidades y no paralizarnos ante las amenazas. Porque lo único inalcanzable es solo aquello que no se intenta jamás. Este espíritu es, precisamente, con el que SEFAC aborda su IX Congreso $\mathrm{Na-}$ cional de Farmacéuticos Comunitarios, que tendrá lugar del 26 al 28 de noviembre en el Palacio Euskalduna de Bilbao, con el lema Haciendo lo difícil, consigues lo imposible/Ezina Ekinez Egina. Un congreso de farmacéuticos que no tienen miedo a lo que deparará el futuro, porque el futuro lo construimos nosotros desde el presente, trabajando con convicción y perseverancia en aquello en lo que se cree: una farmacia comunitaria asistencial, sostenible e innovadora para el buen funcionamiento del sistema sanitario.

El congreso de Bilbao será un congreso en el que los participantes podremos ver que nada es imposible, por muy difícil que parezca, si ponemos toda nuestra energía en conseguirlo y si sabemos trabajar en equipo. Será un congreso en el que analizaremos cómo va a ser ese mundo que viene, protagonizado por la inteligencia artificial, el 
auge de las grandes plataformas online de distribución, los tratamientos personalizados y otros avances tecnológicos que requerirán un gran esfuerzo de adaptación, pero también un refuerzo de nuestra vocación sanitaria como valor diferencial. Será un congreso en el que queremos que la figura del farmacéutico comunitario se vea como la referencia indiscutible en medicamentos, sintomas menores, atención a la cronicidad, prevención, adherencia, etc. Y será un congreso en el que el farmacéutico saldrá revalorizado por su papel fundamental como elemento vertebrador del Estado de Bienestar, tanto como único eje entre el sistema sanitario público y el privado como por ser el profesional de la salud más relevante en el medio rural y el primer y último eslabón de la cadena de atención sanitaria a los pacientes y a la población general.

Todo ello con un programa de actividades que, de nuevo, estamos seguros que volverá a tener un gran respaldo y que superará las cifras de años anteriores en sesiones (mesas redondas, talleres, sesiones prácticas, debates), que contará con nuevos formatos (encuentros con el experto), entidades colaboradoras, comunicaciones y asistentes.
Un congreso que volverá a ser la referencia de la innovación farmacéutica en España y en el que nada de la actualidad del sector, ya sea profesional o científica (indicación farmacéutica, recertificación, nuevas tecnologías, especialidad, dispensación en situaciones especiales, terapias por patologías, servicios profesionales...), se dejará de tratar con rigor y espíritu práctico. Porque queremos que los farmacéuticos que asistan al congreso participen activamente y estén preparados y convencidos de que no hay barreras o dificultades que no puedan superar si se lo proponen.

Si eres farmacéutico y no te conformas ni te asustan los retos, si quieres ampliar tus miras y tener una farmacia comunitaria más partícipe de las grandes decisiones sanitarias, si crees que el farmacéutico comunitario puede tener un papel asistencial mucho más influyente en la sociedad y si crees que los caminos menos fáciles conducen siempre a las mejores recompensas, no te quedes en casa: Bilbao es tu ciudad y \#SEFAC2020 es tu congreso.

¡Contigo lo difícil es mucho más fácil! ¡Contigo lo imposible no es difícil!

Te esperamos en noviembre en Bilbao 2020. ¡Contamos contigo!

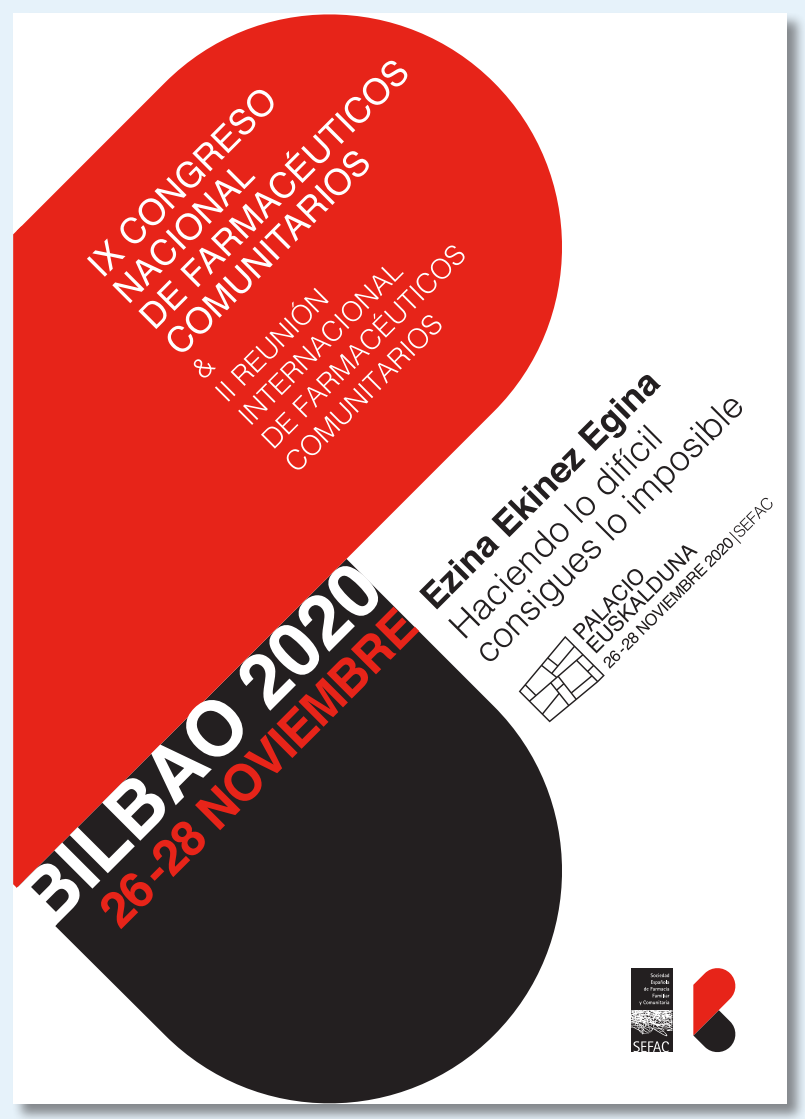

